\title{
Student motivation theory
}

\author{
Angela Bovenko* \\ Don State Technical University, 344002, Rostov-on-Don, Russia
}

\begin{abstract}
The article examines the relevant native and foreign theories of sports activity (SA) motivation. The results of scientific research in this area are analyzed, recommendations for identifying the type and increasing the level of motivation of athletes are presented. Theoretical analysis and generalization of literary data allowed to single out individual demonstrations in the formation of sports motivation, the importance of the influence of self-esteem, the influence of temperament, the influence of the level of anxiety in athletes on the formation of motivation was established. The conditions for the formation of sports motivation have been determined. For high results in sports, the motivation of the athlete at all stages of training has a significant impact. The focus on interpersonal comparison and victory develops competitive motivation, competitiveness. The development of internal and external motivation ensures the formation of goals and objectives of sports activities, favorable stable motives, and leads to the improvement of sports skills. Based on the current literary discussion, we have identified the motives that presumably provide long-term motivation for engaging in sports and the motives that are likely to be perceived as reducing it.
\end{abstract}

\section{Introduction}

For a panoramic review of motivational theories of SA it is necessary to consider the theoretical positions of native and foreign researchers. The high importance of the formation of sports motivation is determined by the achieving top sports results, determines the activity of the individual which is based on motivation.

Sports motivation takes a special place in the psychological support of SA, provoking a person to sport, participate in competitions and move on the way towards victory. Motivation reflects the relevance of the subject with the activity performed. The process of subjective goal-setting and the motivational sphere of an athlete are closely related to each other, and the decisive role is assigned to self-affirmation.

Sports activity is characterized by such psychological characteristics as an orientation to the maximum level of achievements and hard physical, mental and emotional stress associated with the subjective importance of the activity results, struggle and rivalry, publicity of performances in competitions. Long-term and effective engagement in sports depends on the motivational sphere of the individual [1].

\footnotetext{
*Corresponding author: angela.bovenko@yandex.ru
} 
A number of studies are devoted to the study of sports motivation (E.P. Ilyin, A.V. Rodionov, E.G. Babushkin, G.D. Babushkin, R.A.Piloyan A.V. Petrovsky, K.K. I. Stepansky, Yu.Yu. Palalaima, D.B. Cretti, A.C. Puni, R.N. Singer, V.L. Marischuk.)

The concepts analysis on the problem of the formation of sports motivation indicates that while studying the motivation of SA in order to further its formation and preservation in athletes at different stages of training, the coach and psychologist's subject of analysis should be such components of the motivational sphere of an athlete as his motives, goals, needs, emotions.

\section{Results}

In the first studies of the emergence and development of interest in sports, A.C. Puni (1952) established the presence and significance of direct and indirect motives for SA. (satisfaction from muscular activity, aesthetic pleasure, striving for competition), (striving to become strong, healthy, preparation for work, awareness of SA importance).

G. Murray (1930) created the Thematic Apperception Test (TAT) and is the initiator of research on achievement motivation, which in the early 50s of 20th century McClelland and his co-authors transformed it into a tool for measuring motives.

The motives for SA, according to A.V. Rodionov (1989), include the needs for extreme physical efforts, experiencing a state of strong mental tension, overcoming a rival, testing own physical and mental capabilities. Recognized and really acting motives for the subject of SA are the driving force in competitive activity process [2].

The motive and motivation which are the driving force of the individual's activity differ significantly. Motivation is a larger psychological category than motive is and determines the direction of activity. The motive displays the psychological content, the internal picture which reflects the process of personality motivation. It is the motivation that prompts the athlete to sport for a long time, achieving the highest results.

R.A. Piloyan (1998) gives the following definition of motivation: "Motivation is a special state of an athlete's personality which is formed as a result of his correlation of his capabilities with the subject of SA serving as the basis to set and implement goals aimed at achieving the maximum possible sports result at the moment".

Motives are significant mental forces and factors that regulate activity.

A.V. Petrovsky (1987) identifies motive with need. The need is reflected in objects, situations, actions and has its own cognitive structure. The subject's motives are based on his needs.

V.I. Kovalev (1981) emphasizes "The motives of behavior and activity arise at the highest level of reflection of needs - their awareness." The motive determines the end result of the athlete's activity. Needs are determined and are the subject - object relations, while the motive is a purely subjective phenomenon [3].

Let's pay attention to the list of secondary (psychogenic) needs arising on the basis of instinct-like drives as a result of education and training, offered by the American researcher of motivation G. Murray (1938).

These are the needs for achieving success, affiliation, aggression, the need for independence, opposition, respect, humiliation, protection, domination, attracting attention, avoiding harmful influences, avoiding failures, patronage, order, game, rejection, understanding, sexual relations, help, mutual understanding. These needs directly lead to the formation of competitive motivation.

It is necessary to distinguish competitive and sports motivation. Competitive motivation is reflected in all spheres of human life and activity, there is a need for rivalry but not every person has competitive motivation. Sports motivation is peculiar to all athletes and manifests itself at every stage of training and competitive activity [4]. 
K.K. Platonov (1982) considers motive as a mental phenomenon that becomes an incentive to a certain activity. Mental processes, states, properties can be as a motive.

In H. Heckhausen (1986) studies he points to the internal and external factors of a person prompting him to activity.

Let's consider the formation of a motive using the classification proposed by E.P. Ilyin (1990). The motives nascent stages are stepwise and are divided into general and specific ones. The general motives for physical education include chaotic desires to train without fixation on a definite kind of sport. Specific motives include the choice of a certain kind of sport and the desire for in-depth training and achievement of the goals set. E.P. Ilyin described the signs of athletes with high and low levels of ambition and the corresponding pre-start excitement. If the level of aspiration is high (for example, the athlete plans to be in the national team), then the pre-start excitement will be strongly expressed. An athlete with a high level of aspirations is distinguished by an overestimation of their physical and mental capabilities; in case of failure they experience stress and anxiety. Athletes with a low level of aspirations inadequately assess their capabilities, they have emotional instability, underestimate themselves, and are afraid of failures [5].

Also let's consider the structure of sports motivation in accordance with the ideas of R.A. Piloyan (1998) which contains the following grounds.

Incentives that reveal the fundamental orientation of the athlete to meet spiritual needs and the athlete's orientation to meet material needs. Material orientation is often the leading one in the motivation of an athlete. However, activities motivated only by material needs cannot be sustainable.

Competition is one of the key aspects of traditional sports. It is established that competition provides enjoyment of the training and competitive process, forming the motive of satisfaction.

There are basic reasons that include three factors.

The first factor reflects the degree of an athlete's interest in favorable social conditions of SA. The second factor reflects the degree of an athlete's interest in the accumulation of knowledge, abilities and skills necessary for successful competitive activity. The third factor reflects the degree of an athlete's interest in the absence of injuries and pain.

Procedural grounds contain the following below mentioned factors. The first factor reflects the degree of an athlete's interest in accumulating knowledge about his rivals, which stimulates competitive motivation. The second factor reflects the degree of an athlete's interest in the absence of psycho-traumatic factors that can have a negative impact in the process and in the result of competitive activity [6].

E.G. Babushkin (1998) distinguishes training and competitive motivation in the sports motivation structure. Thus, there are two components in competitive motivation: motivation to achieve success and motivation to avoid failure.

Athletes with a dominant motivation for achieving success are distinguished by their desire to win, the ability to endure pain and fight to the finish, positive emotions, tendency to dominate, evident sports aggression, desire to take risks, insensitivity to threat, low anxiety, aggressive and attacking style of combat, ability to manage their psychophysiological regulation mechanisms, high intensity of stress and the effectiveness of behavior in extreme situations. It has been established that the motivation for achieving success affects the goal and content of the action, the intensity of stress and behavior in extreme situations.

The motivation to avoid failure encourages the athlete to make as few misses, mistakes, losses as possible. The athlete develops fear and excitement before the competition, which is one of the reasons for the failure-avoiding behavior [7].

Let us review the research of V.I. Stepansky (1981) which reflects the ratio influence of the motive to achieve success and the motive to avoid failure on the results of activities. If 
the motivation for success prevails over the motivation to avoid failure, the performance of the subject is determined by his psychophysiological characteristics. In case if motivation for avoiding failure prevails over the motivation for success, the performance of the subject will be low.

To study the ratio of motivation to achieve success and avoidance of failure, V.I. Stepansky proposes a method of "tracking a moving object" using an electric stopwatch. After the obtained data, a conclusion is made about the predominance of one or another athlete's motivation. This method is quite informative and allows you to competently build the concept of sports motivation management for each athlete.

To achieve high results in SA it is necessary to study motivation at each stage of longterm training of an athlete: at the initial stage of training, at the stage of basic, preliminary training, initial sports specialization, in-depth specialization, sports perfection [8].

Various methods are used to study sports motivation. Analyzing the position of this issue in sports psychology, we can distinguish three groups of methods for the sports motivation research. The first group of methods is projective tests. In practice, the most common and reliable is the second group of methods which includes questionnaires and interviews. The third group of methods includes Y.Y. Palalaima (1974) method of indirect assessment of motivation power. With the help of this method, the strength of a moral motive (a sense of collectivism) is determined through an assessment of the effectiveness of an athlete's actions. Y.Y. Palalaima established a relevance between motivation and the level of anxiety experienced by an athlete, the conclusions are as follows: the greater the strength of the motive (the desire to achieve maximum results, or fear of failure), the more anxious the athlete [9].

Sports motivation is defined as the actual state of the athlete's personality, it is impossible to plan and implement goals aimed at achieving the highest result of competitive activity without it. The results of researchers R.N. Singer, V.L. Marischuk (1980), indicate that the maximum level of motivation is not always required to complete all the tasks of all people. For athletes an increased motivation increases excitement and tension. When choosing a working strategy for each athlete, a coach should take into account his optimal level of motivation.

The demonstration of sports motivation depends on the characteristics of athletes' selfesteem of their own personal qualities. According to A.V. Shaboltas (1997) research results significant features of self-esteem, regardless of the sport and gender of athletes are selfconfidence, satisfaction with sports results, authority, health. In particular, it was revealed that self-confidence is closely related to sports achievements, the motive to achieve success and the emotionality of SA [10].

E.G. Babushkin (2014) described individual demonstrations in the formation of sports motivation. The influence of temperament on the formation of motivation is manifested in the below mentioned items. A more intensive formation of sports motivation is observed in representatives of choleric and sanguine types of temperament compared with phlegmatic and melancholic types. Representatives of a melancholic temperament do not show a decrease of motivation level "to avoid failure".

Personal anxiety affects the formation of competitive motivation. Persons with increased anxiety have the lowest rates in the formation of motivation "to achieve success" in comparison with persons with an average level of anxiety.

The need for self-improvement is demonstrated in the formation of incentive bases for motivation. Athletes with a high level of this need have higher growth rates in orientation to the spiritual and material needs' satisfaction compared with persons with a lower level of need for self-improvement [11].

The development of sports motivation, the emergence of a new motivational "background" go beyond the limits of the activity performed by the subject, go ahead of it. 
In the development of the athlete's personality there is a process of changing the content and dynamic sides of motivation, this originates from the influence of changes in mental and physical stress, forms of training activity. Significant here is the coach's organization of sports activity, gradually leading the subject (athlete) beyond the existing needs, levels of aspiration and the formation of new motives for achieving success [12].

Figure 1 shows the authors of current domestic and foreign theories of sports motivation.

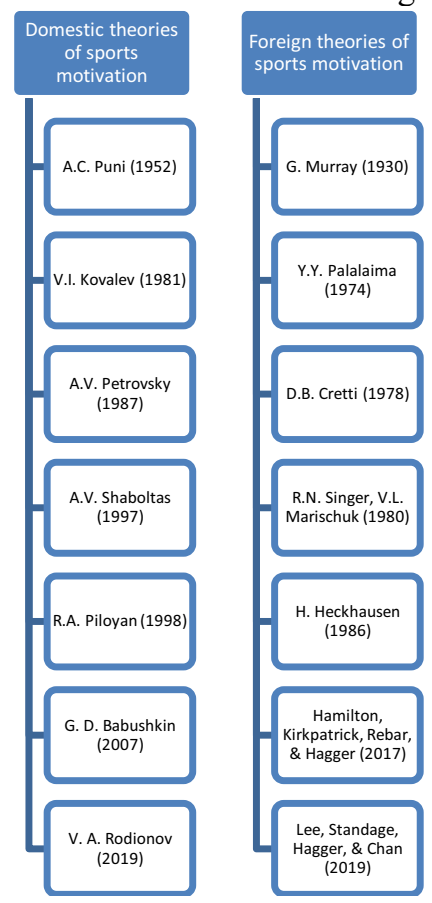

Fig. 1. Domestic and foreign theories of sports motivation

It is known that the highest sports result is participation and victory in the Olympic Games. The challenge of an athlete to get into the national team of his country does not appear instantly, it is necessary to go through all the stages of many years of sports training. The dominant strategy of psychological support for the preparation of athletes for competitions is the need of long-term systematic work aimed at developing psychological resources of competitiveness, as well as sustainable motivation for sports motivation.

E.G. Babushkin highlights the formation of sports motivation at all stages of sports training. At the stage of initial training two directions are noted in the formation of motivation: the use of motivational trainings and the satisfaction of actual needs. At this stage training of causal schemes, personal causality, self-motivation, training of achievement motivation are relevant. The management of sports motivation at this stage through the satisfaction of actual needs helps to strengthen the confidence, collectivism, self-respect in young athletes, positive attitude to training sessions and a coach-teacher, readiness for further development.

The formation of sports motivation at the stage of fundamental sports specialization of athletes is characterized by focusing on achieving high sports results which have a significant impact on the preservation of sports motivation. The priority tasks at this stage are the study of the reasons for success and failure in competitions, the formation of stable self-esteem among athletes, the formation of the optimal ratio of training and competitive motivation among athletes; the consolidation of a beneficial interpersonal relationship with the coach between athletes and within the team. 
Activation of sports motivation among highly qualified athletes, members of national teams. The special status of the competition, inadequate assessment of the significance of certain conditions of the tournaments is a source of mental tension, affects the psychomotor state of an athlete. To activate the sports motivation of an athlete physiotherapeutic, hardware and psychopharmacological means are used. Formation of a worldview through the formation and development of modern views on the cultural and historical roots of sports in general and the chosen type in particular [13].

As a rule, highly qualified athletes are aware of their personal experience of motivational schemes (attitudes, behavioral patterns), have ideas and ways and methods of satisfying an actual need and how to satisfy it.

To achieve the maximum result of competitive activity it is necessary to take into account the dynamics of changes in the motivation at all stages of sports training.

\section{Discussion}

Modern researchers of sports motivation G. D. Babushkin, B. P. Yakovlev, V. G. Radionova, V. G. Savitsky point out the need to identify motivational processes that support positive involvement in sports, the desire for personal effectiveness and skill.

It was revealed that on the one hand, motivation affects the nature of training activity and certainly on the competitive result, on the other hand, an effectiveness increase of the competitive activity enhances sports motivation. Motivation for SA includes motivation for training activities and competitive motivation, which differ in content, goals, and results.

To understand the individual motives for doing sports and the successful work of a particular athlete, American psychologist D.B. Cretti (1978) suggests collecting information considering social status, emotional structure and his attitude to the current situation. If parents (guardians, caregivers of children) always set clear and easily achievable goals for the child and provided him with assistance, most likely there will be a low level of need for success. Provided that the child's parents (guardians, caregivers of children) have never praised or rewarded kids for their success, there will be low needs for achievement [14]. If parents (guardians, guardians of children) set difficult, but feasible tasks for the child and left him to achieve success himself and then praised him, then he will most likely have a high need for success, which will positively affect his attitude to sports.

Coaches most often have to work with athletes who have already formed the basic needs to achieve success and the orientation of their activities. D.B. Cretti recommends coaches to be democratic with athletes and involve them in a careful analysis of the training content in an attempt to understand the meaning of the proposed regimes and to promote more active work in situations that allow them to demonstrate independence.

The analysis of the motivational theories of domestic and foreign researchers shows that there is no generally recognized and practical structure of the formation of sports motivation, motives for SA, competitive motivation and classification of needs.

\section{Conclusion}

The structure of motivation of the competitive activity of athletes at different stages of training is formed by internal and external factors, the most evident components of them are: 1) the need for competitive motivation; 2) motives for competitive activity; 3 ) development of character and mental qualities; 4) material motives and prestige [15].

An essential component of the motivation for SA is the motivational-energy component which manifests itself in a stable love for sports, desire for competition, personal sense when doing sports, full return of strength in training and competition. 
In the formation of motivation, motivational trainings are widely used in various fields of human activity.

An internal motive arises in the activity itself, it is a direct result, a product of the interaction of a person and his environment, and is always shown in direct personal experiences. The formation of spiritual motives contributes to a more successful sports career than external motives. In any kind of sport the characteristic features of motivation are highlighted. Thus, the diagnosis and formation of sports motivation for a particular sport will have its own specificity.

In case of independent motives formation in SA, an athlete needs to organize himself and his SA as follows: choose meaningful and really achievable situational and promising goals, apply self-hypnosis and positive imagination, use mental training to strengthen motives, develop will and self-discipline.

At the initial stages of doing sports, procedural motivation is considered the most effective. The main point in the formation of motivation for the achievement of young athletes is a positive interaction between parents (guardians, guardians of children), significant adults, coaches and a psychologist [16]. High motivation for achievement is formed in children whose parents are constantly raising the level of their claims skillfully assisting them, showing at the same time gentleness and warmth in communication with them [17]. A low level of achievement motivation is formed in those children whose parents exercised too strict supervision, directive guardianship over them, or were indifferent to them.

\section{References}

1. Derwin King, Chung Chan, Lei Zhang,Martin S. Hagger, Psychology of Sport and Exercise 48, 101660 (2020). doi.org/10.1016/j.psychsport.2020.101660

2. V.A. Rodionov, V.G. Radionova, V.G. Savitsky, Sports psychology (Yurayt Publishing House, 2019).

3. L.K. Serova, Motivation in sports activities (Monograph, Sport, Moscow, 2020).

4. G.B. Gorskaya, Psychological support of long-term training of athletes (Publishing house, Krasnodar, 2008).

5. E.P. Ilyin, Sports psychology (Peter, Moscow [and others], 2008).

6. V.V. Kozin, A.A. Geras'kin, A.V. Rodionov, Omsk Scientific Bulletin 1, 125 (2014).

7. G.D. Babushkin, V.N. Smolentseva, Psychology of physical culture and sport (SibGUPK, Omsk, 2007).

8. G.D. Gorbunov, Psychology of physical culture and sport (Publishing house "Academy", 2009).

9. M.M. Zagainov, Psychological skill of a trainer and an athlete (Publishing house "Soviet Sport", 2006).

10. A.V. Shaboltas, D.A. Zhukov, Pedagogy, Psychology, Sociology 1, (2011).

11. E.B. Babushkin, A.P. Shumilin (Publishing house "Sport", 2016)

12. Amon Rappa, LiaTirabeni, International Journal of Human-Computer Studies 140, 102434 (2020). doi.org/10.1016/j.ijhcs.2020.102434

13. G.D. Babushkin, B.P. Yakovlev, Omsk Scientific Bulletin 5, (2013).

14. E.V. Vorobyeva, P.N. Ermakov, E.F. Borokhovski, et al., Association between categorization of emotionally-charged and neutral visual scenes and parameters of eventrelated potentials in carriers of different COMT, HTR2A, BDNF gene genotypes 
[version 2; peer review: 2 approved], F1000Research 9:446, (2020). doi.org/10.12688/f1000research.22503.2

15. V.V. Andreev, Theoretical, Scholarly notes of the University named after P.F 4,122 (2015).

16. Yu. Kul, M. Storch, The power of your own "I". Seven psycho-gymnastics for the unconscious (Publishing house Humanitarian Center, 2015)

17. E. Azarko, I. Abakumova, I. Kupriyanov, Assessment of resource and self-regulation of behavior of students with different sense-forming strategies during the exam period in remote format behaviour, E3S Web of Conferences 210, 9 (2020). Article 18004. (Innovative Technologies in Science and Education (ITSE-2020), Divnomorskoe village, Russian Federation, August 19-30, 2020). https://www.e3sconferences.org/articles/e3sconf/abs/2020/70/e3sconf_itse2020_18004 /e3sconf_itse2020_18004.html 